\title{
Synthesis and Characterization of Zeolites Produced by Ultrasonication of Coal Fly Ash/NaOH Slurry Filtrates
}

\author{
Tebogo M.A. Mokgehle ${ }^{\mathrm{a},}$ Wilson M. Gitari ${ }^{\mathrm{b}}$ and Nikita T. Tavengwa ${ }^{\mathrm{a}, *}(\mathbb{D}) \S$ \\ ${ }^{a}$ Department of Chemistry, School of Mathematical and Natural Sciences, University of Venda, Private Bag X5050, \\ Thohoyandou, 0950, South Africa. \\ ${ }^{b}$ Department of Ecology and Resource Management, School of Environmental Sciences, University of Venda, \\ Private Bag X5050, Thohoyandou, 0950, South Africa. \\ Received 27 January 2019, revised 5 February 2020, accepted 12 February 2020.
}

\begin{abstract}
Studies were conducted to determine if crystalline zeolites could be obtained from the filtrates of coal fly ash (CFA)/NaOH slurries through sonication. The CFA/ $\mathrm{NaOH}$ slurries were obtained by aging CFA in $3 \mathrm{M} \mathrm{NaOH}$ for $24 \mathrm{~h}$ at $50{ }^{\circ} \mathrm{C}$ using a solid/ liquid (S/L) ratio of $15 \mathrm{~g} / 120 \mathrm{~mL}$. FT-IR studies indicated that the ' $\mathrm{Lo}^{\prime}$ regime ultrasonicated zeolite had higher intensities than that of the ' $\mathrm{Hi}^{\prime}$ frequency ultrasonicated zeolite. The bands associated with the 'Lo' regime ultrasonicated zeolite were observed at $1066 \mathrm{~cm}^{-1}, 1400 \mathrm{~cm}^{-1}$ and $3600 \mathrm{~cm}^{-1}$, which were identified as $\mathrm{Si}-\mathrm{O}$ asymmetric stretch, Al-O asymmetric stretch, O-H bend and O-H asymmetric stretch, respectively. Based on PXRD studies, the zeolitic phases were most intense for the 90 min ultrasonicated zeolite. Powder X-ray diffraction studies showed that the phases initially in CFA, such as quartz and aluminosilicate, were converted into gismodine zeolite Na-P1. Morphological changes were seen as ultrasonication period was increased. At short ultrasonication times, irregularly shaped fused-like grain structures were observed, while at longer times separate grain-like structures became more apparent. Energy dispersive X-ray spectroscopy studies on the 90 min ultrasonicated zeolite indicated the presence of $\mathrm{Na}, \mathrm{O}, \mathrm{Si}$ and $\mathrm{Al}$, which were important building-blocks for the zeolites.
\end{abstract}

KEYWORDS

Ultrasonication, zeolites, ageing, coal fly ash, crystallization.

\section{Introduction}

The application of ultrasonication is an attractive area of study for many researchers, due to its positive influence on crystallization. ${ }^{1-4}$ Ultrasonication involves the conversion of an electrical signal into physical vibrations directed towards a substance. This method has useful advantages in that it is fast, simple and does not require complicated facilities. ${ }^{5}$ This technique has been reported to control nucleation, improve particle size distribution and morphology. ${ }^{6-7}$ Additionally, ultrasonication has been observed to improve crystal growth, ${ }^{8}$ induction periods, ${ }^{9}$ nucleation ${ }^{6}$ and yields of crystalline zeolitic products. ${ }^{10}$ The mechanism of ultrasonication has been studied over the past several decades. Cravotto et al. 7 reported that ultrasonic waves are transmitted from a sound source through liquids causing oscillation to take place in the direction of the wave, producing longitudinal waves. This then results in the layer of liquid closest to the ultrasound source to be displaced, followed by displacement and compression of neighbouring layers. ${ }^{11-12}$ The molecules within these layers also become compressed resulting in pressure changes causing the molecules to undergo geometrical changes due to bond stretches. Thereafter, bond stretches form bubbles (cavities) that when molecules try to regain their initial position, make the cavities collapse, otherwise known as cavitation. ${ }^{7}$ It is through this cavitation that attractive forces between molecules are disrupted paving the way for new reactivities leading to the formation of new species with unique morphologies and size distribution of crystals. ${ }^{7}$ This energy propels initiation of nucleation which is responsible for crystal growth. ${ }^{13}$ The use of sound waves to obtain highly crystalline zeolites is a sought-after

* To whom correspondence should be addressed. E-mail: nikita.tavengwa@univen.ac.za technique; however, research has lately been focused on generating zeolites from renewable sources.

Coal fly ash (CFA) is a coal combustion by-product abundant in elements such as $\mathrm{Al}$ and $\mathrm{Si}$, with traces of $\mathrm{Ca}$, $\mathrm{K}$ and $\mathrm{Na}$ amongst others. CFA generally has a spherical morphology and its composition is dependent on the combustion conditions. CFA zeolites are materials obtained from the dissolution of the CFA matrix using an alkaline activating agent and subsequent crystallization of the matrix solution.

Though work has been done on the synthesis of zeolites from CFA using ultrasonication techniques, this work is focused on the synthesis of crystalline zeolitic products from the filtrates of $\mathrm{CFA} / \mathrm{NaOH}$ slurry through ultrasonication. Aspects such as purity, crystalline size, morphology and yield were evaluated. Additionally, this study was aimed at addressing the environmental threat caused by the disposal of the $\mathrm{CFA} / \mathrm{NaOH}$ filtrate common to the hydrothermal treatment technique of CFA.

\section{Experimental}

\subsection{Chemicals}

Sodium hydroxide pellets were obtained from Rochelle Chemicals (Johannesburg, South Africa) and were used as alkaline activating agents for dissolution of the aluminosilicate matrix in CFA. $\mathrm{Al}_{2}\left(\mathrm{SO}_{4}\right)_{3} \cdot 18 \mathrm{H}_{2} \mathrm{O}$ and $\mathrm{SiO}_{2}$ were purchased from Associated Chemical Enterprises (Johannesburg, South Africa) and Sigma-Aldrich (Johannesburg, South Africa), respectively, and were used as standards in the analysis of dissolved $\mathrm{Si}^{4+}$ and $\mathrm{Al}^{3+}$ species in the alkaline solution using the graphite furnace atomic adsorption spectrometer (GFAAS). Ultra-pure water with conductivity and resistance of $0.055 \mu \mathrm{S} \mathrm{cm}^{-1}$ and $18.2 \mathrm{~m} \Omega$, respec- 
tively, was obtained from a Direct-Q 5UV distiller (Vienna, Austria) and was used for the preparation of $\mathrm{NaOH}$ solutions.

\subsection{Materials}

Sonication studies were done using a Labotech Scientech Ultrasonic Cleaner Model-704 (Johannesburg, South Africa). Crystallization studies were performed using a 278AC Brass Parr Bomb obtained from the Parr Instrument Company (Illinois, United States of America). A Labotec Ecotherm oven (Johannesburg, South Africa) was used for crystallization of zeolites. X-ray fluorescence (XRF) analysis was conducted using a Bruker AXS S2 Ranger spectrometer (Karlsruhe, Germany). Powder X-ray diffraction (PXRD) studies were conducted on a Siemens D2 diffractometer (Cramerview, South Africa) using Co $\mathrm{K} \alpha$ radiation equipped with a Ni filter, steps of $0.02^{\circ}$ with a scan range of $10-90^{\circ}$. The morphological features of the samples were evaluated by scanning electron microscopy (SEM) (FEI Nova Nanolab 600) (Hillsboro, United States of America), by placing powdered samples on an aluminium sample stub via double-sided carbon tape as the adhesive and coat it with gold. Fourier transform infrared (FT-IR) spectroscopy was performed using a Bruker Alpha Platinum-ATR analyzer (Billerica, United States of America) to evaluate the absorption bands in the ultrasonicated materials. Brunauer-Emmett-Teller (BET) was done using a Horiba (Kyoto, Japan) SA-9600 analyzer to measure the specific surface area of the prepared materials. The samples $(0.35-0.50 \mathrm{~g})$ were first de-gassed before analysis at $110{ }^{\circ} \mathrm{C}$ using helium gas Nitrogen gas was then used as an adsorbate at $-195.8^{\circ} \mathrm{C}$.

\subsection{Methods}

Fresh pulverized CFA was collected from precipitators of the Modderfontein steam plant, South Africa. The CFA samples were stored in polyethylene containers away from direct sunlight. This was done to minimize exposure to the atmosphere to maintain their initial overall phase composition.

During the ageing stage, a $3 \mathrm{M}$ solution of $\mathrm{NaOH}$ was prepared by dissolving $29.963 \mathrm{~g}$ of sodium hydroxide in $250 \mathrm{~mL}$ ultra-pure Milli-Q water with a conductivity of $0.05 \mathrm{mS}$ and resistance of $18 \mathrm{~m} \Omega .120 \mathrm{~mL}$ of the prepared $\mathrm{NaOH}$ solution was then mixed with CFA $(15.0 \mathrm{~g})$. The mixture was stirred at $800 \mathrm{rpm}$ for $24 \mathrm{~h}$ at $50{ }^{\circ} \mathrm{C}$ in a $250 \mathrm{~mL}$ polypropylene sealable bottle to allow for the dissolution of $\mathrm{Si}^{4+}$ and $\mathrm{Al}^{3+}$ from the CFA material into the $\mathrm{NaOH}$ activating solution, producing a slurry.

The aged $\mathrm{CFA} / \mathrm{NaOH}$ slurries were filtered by gravity filtration using Grade 1 Whatman filter papers resulting in a pale yellow clear filtrate solution that was collected in $50 \mathrm{~mL}$ centrifuge tubes. Studies were then done on the filtrates to determine if any zeolites could be obtained by ultrasonication. This was done by placing the filtrate containing centrifuge tubes in an ultrasonic cleaner. The following variables were evaluated; ultrasonication frequency, ultrasonication time and temperature. The filtrates were subjected to ' $\mathrm{Hi}$ ' and 'Lo' frequency settings. These frequency settings affected the size and spread of the cavitation bubbles, influencing the erosion and sonication action on the surfaces of the sonicated material. The ' $\mathrm{Hi}^{\prime}$ setting provided minimal erosion of surfaces, while the 'Lo' setting was more aggressive. The power was set at 150 and $300 \mathrm{~W}$ for 'Hi' and 'Lo' frequencies, respectively. Once an optimized frequency was obtained, ultrasonication time studies were conducted. The sonication periods ranged from 30-210 min. All sonication studies were conducted at room temperature. After the optimized frequency and ultrasonication time was obtained, the filtrate $(20 \mathrm{~mL})$ was then crystallized using a 278AC Brass Parr Bomb at $140{ }^{\circ} \mathrm{C}, 180^{\circ} \mathrm{C}$ and $230^{\circ} \mathrm{C}$ for a period of $12 \mathrm{~h}$. This time was also used by Mokgehle et al. ${ }^{14}$ in previous studies. White crystalline solids were obtained. The $\%$ yield of the solids was calculated as shown in Equation 1.

$$
\text { Percentage yield }=\left(\frac{\text { mass of zeolite obtained }}{\text { mass of CFA used }}\right) \times 100
$$

\section{Results and Discussion}

\subsection{Effect of Ultrasonication Frequency on Filtrates of Coal Fly Ash/NaOH Slurries}

Sonication studies were done on the filtrates of the $\mathrm{CFA} / \mathrm{NaOH}$ slurries to evaluate the possibility of obtaining pure zeolites before crystallization. At first, crystallization temperatures of $140^{\circ} \mathrm{C}$ and $180^{\circ} \mathrm{C}$ were attempted; however, the ultrasonicated solution was still present, indicating no crystallization. It was then decided to conduct crystallization at higher temperatures; in this case at $230^{\circ} \mathrm{C}$. Following this, white crystalline solids were obtained. Hence, a crystallization temperature of $230{ }^{\circ} \mathrm{C}$ was used for all the experiments in this work. Fig. 1 shows the FT-IR spectra of CFA and the zeolite products as the frequency was varied. It was observed that the band at $1066 \mathrm{~cm}^{-1}$, due to $\mathrm{Si}-\mathrm{O}$ and $\mathrm{Al}-\mathrm{O}$ asymmetric stretches became intense and shifted towards low frequencies $\left(875 \mathrm{~cm}^{-1}\right)$ in the zeolite samples. Other researchers observed a similar trend. ${ }^{15-16}$ Additionally, for the zeolite ultrasonicated at ' $\mathrm{Lo}^{\prime}$ frequency and crystallized at $230^{\circ} \mathrm{C}$, the $\mathrm{Si}-\mathrm{O}, \mathrm{Al}-\mathrm{O}$ symmetric stretches and $\mathrm{Al}-\mathrm{O}$, Si-O bends were observed in the regions of $804-805 \mathrm{~cm}^{-1}$ and $500-550 \mathrm{~cm}^{-1}$, respectively. Furthermore, the band at about $1400 \mathrm{~cm}^{-1}$ correspond to stretching vibrations of $\mathrm{Si}-\mathrm{O}$ bonds in $\mathrm{SiO}_{4} \cdot{ }^{16}$ The band at $700 \mathrm{~cm}^{-1}$ for both the ' $\mathrm{Hi}^{\prime}$ and 'Lo' regime ultrasonicated zeolites indicated that $\mathrm{Si}$ is liberated from the zeolite framework and is substituted by additional $\mathrm{Al}$ and $\mathrm{Na} .{ }^{16}$ This also indicated that the glassy aluminosilicate layer of CFA reacted with the $\mathrm{NaOH}$ activator to form zeolites. ${ }^{15}$ Comparison of FT-IR spectra of separately treated ' $\mathrm{Hi}$ ' and ' $\mathrm{Lo}$ ' regime ultrasonicated materials in Fig. 1 showed that the 'Lo' regime ultrasonicated zeolite had higher intensities than that of the 'Hi' frequency ultrasonicated zeolite at $1066 \mathrm{~cm}^{-1}, 1400 \mathrm{~cm}^{-1}$ and $3600 \mathrm{~cm}^{-1}$. Furthermore, the 'Lo' regime material was observed to generate cavitation bubbles which formed high energy shock waves, that probably changed the initial molecular arrangement in the aluminosilicate glassy layer. ${ }^{7}$ Additionally, the separately treated ' $\mathrm{Hi}^{\prime}$ and 'Lo' regime ultrasonicated materials were observed to be hygroscopic, which is in agreement with the band due to

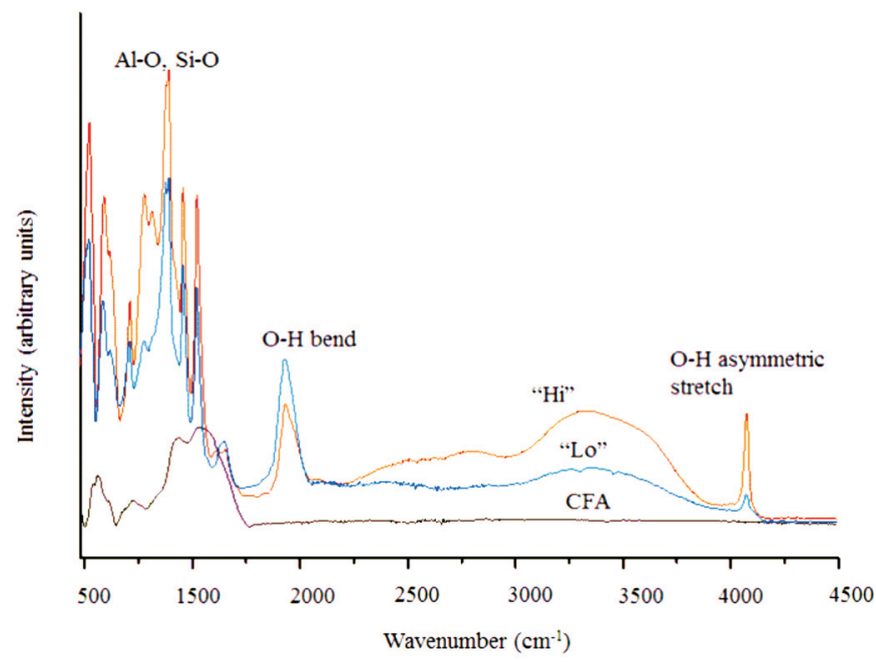

Figure 1 FT-IR spectra of CFA and the zeolites produced at $230{ }^{\circ} \mathrm{C}$ after $12 \mathrm{~h}$ ultrasonic treatment of separate filtrates at ' $\mathrm{Hi}^{\prime}$ and ' $\mathrm{Lo}$ ' frequencies. 

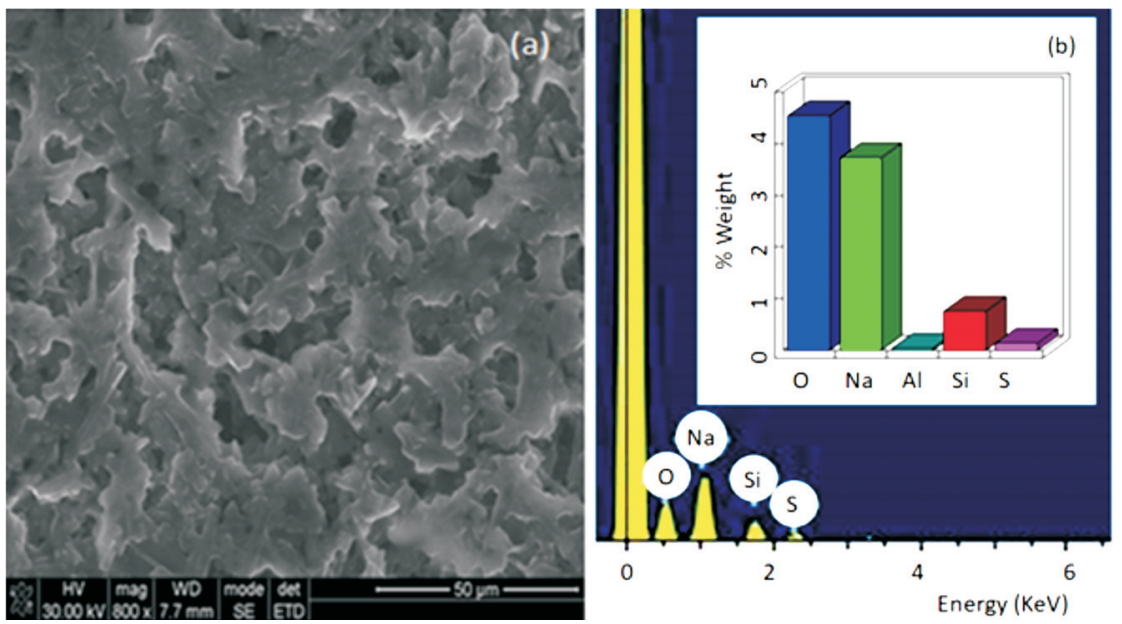

Figure 2 (a) SEM of 60 min ultrasonicated zeolite done at 'Lo' frequency at $\times 800$ magnification and (b) the respective EDS spectrum (inset shows the relative percentages of elements).

$\mathrm{O}-\mathrm{H}$ bend at $1450 \mathrm{~cm}^{-1}$ and $\mathrm{O}-\mathrm{H}$ asymmetric stretch around $3000 \mathrm{~cm}^{-1}$. The best zeolite material was produced from the $\mathrm{CFA} / \mathrm{NaOH}$ filtrates treated with the 'Lo' regime and crystalized at $230^{\circ} \mathrm{C}$. This material was used for further crystallization studies.

The 'Lo' regime ultrasonicated material was further characterized by SEM-EDS, as shown in Fig. 2. Fig. 2a shows the SEM images taken at $\times 800$ magnification, showing fused-like particles with an intricate network of channels. The EDS spectrum (Fig. 2b) indicated the presence of $\mathrm{Na}, \mathrm{O}, \mathrm{Si}$ and $\mathrm{S}$. The dominant elements ( $\mathrm{Na}$ and $\mathrm{O}$ ) in the material were observed to be from the $\mathrm{CFA} / \mathrm{NaOH}$ mixture that was filtered. The detection of $\mathrm{Si}$ in the sonicated material was due to the dissolution of $\mathrm{Si}^{4+}$ into the alkaline $(\mathrm{NaOH})$ solution during ageing of CFA (Fig. 2b). Murayama et al..$^{17}$ and Jha et al. ${ }^{18}$ reported that the $\mathrm{OH}^{-}$from the $\mathrm{NaOH}$ activating agent contributed significantly to the dissolution of $\mathrm{Si}^{4+}$ and $\mathrm{Al}^{3+}$ from CFA. It was observed that $\mathrm{Al}$ from the aged CFA was present in trace amounts of about $0.1 \%$ (inset in Fig. $2 b$ ) though it could not be detected on the EDS spectrum (Fig. 2b). The EDS spectrum also indicated the presence of S, which was most likely to have originated from the parent coal material of the CFA. The parent coal material probably had sulfides in the form of pyrite $\left(\mathrm{FeS}_{2}\right)$ or marcasite $\left(\mathrm{FeS}_{2}\right) \cdot{ }^{19}$

Powder X-ray diffraction (PXRD) studies were done to determine the zeolitic phases obtained under 'Lo' regime ultrasonic frequencies and examine the conversion of the CFA aluminosilicate and quartz phases. The PXRD spectrum of the zeolite crystallized at $230^{\circ} \mathrm{C}$, after an ultrasonication treatment done at 'Lo' frequency for $60 \mathrm{~min}$, is shown in Fig. 3. The sharp peaks in Fig. 3 indicated the crystalline nature of the zeolite, as reported by Vijaya et al. ${ }^{20}$ The dominant mineral phases observed was that of gismodine zeolite Na-P1 $(2 \Theta 17,25,28,34,26,40,48,52,54$, $65,87)$. Musyoka et al. ${ }^{21}$ and Vadapalli et al. ${ }^{22}$ also reported the characteristic $2 \Theta$ values for zeolite Na-P1.

\subsection{Effect of Ultrasonication Time on Filtrates of Coal Fly Ash/ $\mathrm{NaOH}$ Slurries}

\subsubsection{FTIR Investigation}

Figure 4a shows FTIR spectra of the zeolites obtained as a function of ultrasonication time, which were then subjected to the $230{ }^{\circ} \mathrm{C}$ hydrothermal treatment step. Similar patterns were observed for all the spectra, with the 120 min ultrasonicated zeolite generally having the highest intensities of peaks in the region of $500 \mathrm{~cm}^{-1}$ to $1200 \mathrm{~cm}^{-1}$ (Fig. 4c). This probably indicated that ultrasonication for longer periods played a role in the general increase in peak intensities at $710 \mathrm{~cm}^{-1}$ and $810 \mathrm{~cm}^{-1}$ associated with $\mathrm{Si}-\mathrm{O}$ and Al-O symmetric stretches, respectively. This was seen with the relatively lower intensities of the $180 \mathrm{~min}$ and $210 \mathrm{~min}$ spectra relative to the shorter (<90 $\mathrm{min}$ ) ultrasonication times, (Fig. 4c). Fig. 4b is a comparison of CFA and the $60 \mathrm{~min}$ ultrasonicated zeolite, the band at $1100 \mathrm{~cm}^{-1}$ for the zeolite is due to internal $(\mathrm{Si}, \mathrm{Al}) \mathrm{O}_{4}$ tetrahedral asymmetrical stretching.

In Fig. 4c the regions of $570-630 \mathrm{~cm}^{-1}$ and $880-920 \mathrm{~cm}^{-1}$ were assigned to a $(\mathrm{T}-\mathrm{O})(\mathrm{T}=\mathrm{Si}, \mathrm{Al})$ bend and a $\mathrm{Si}-\mathrm{O}, \mathrm{Al}-\mathrm{O}$ tetrahedral vibration, respectively. Additionally, as the ultrasonication time was increased, the bands characteristic for asymmetric Si-O and $\mathrm{Al}-\mathrm{O}$ stretch at $1100 \mathrm{~cm}^{-1}$ moved toward higher energy, as observed by Musyoka et al. ${ }^{21}$ and Fernández-Jiménez et al. ${ }^{23}$ This signified that increasing the ultrasonication time strengthened the $\mathrm{Si}-\mathrm{O}$ and $\mathrm{Al}-\mathrm{O}$ network structure in the zeolite as shown in Fig. 4.

\subsubsection{PXRD Investigation}

A series of ultrasonication studies were conducted on the filtrates obtained from the aged slurries at ' $\mathrm{Lo}^{\prime}$ frequency setting, which were then subjected to crystallization at $230^{\circ} \mathrm{C}$ (shown in the PXRD spectra in Fig. 5). Additionally, in the absence of

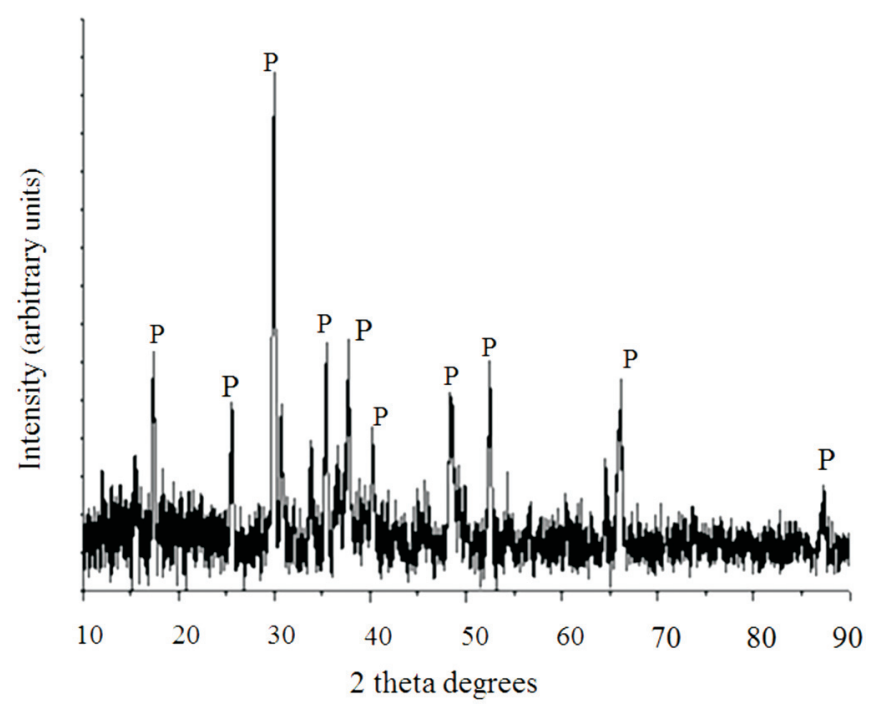

Figure 3 PXRD spectrum of the zeolite crystallized at $230{ }^{\circ} \mathrm{C}$, after an ultrasonication treatment was done at 'Lo' frequency for $60 \mathrm{~min}$. The label 'P' indicates zeolite Na-P1. 

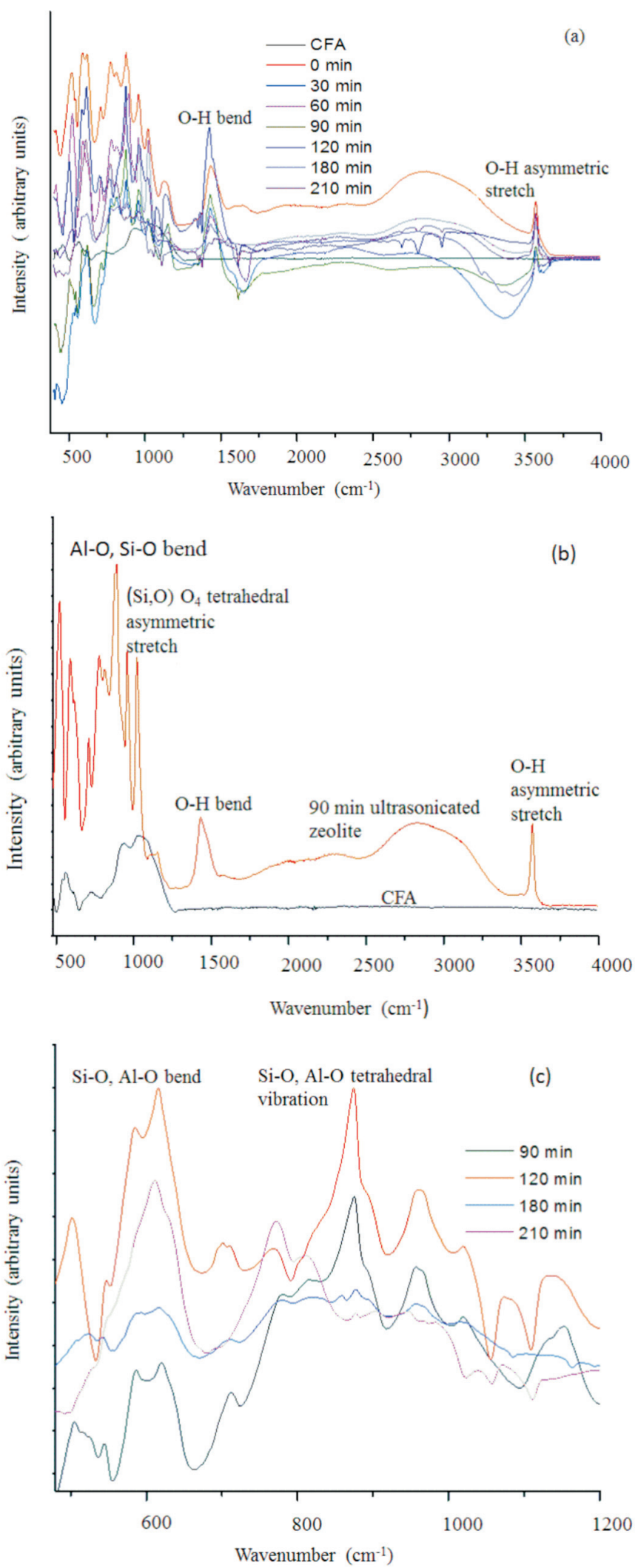

Figure 4 FT-IR spectra of CFA and the zeolite produced at $230^{\circ} \mathrm{C}$ after an ultrasonication treatment done at ' $\mathrm{Lo}^{\prime}$ frequency and at different times: (a) full scan; (b) CFA and 60 min ultrasonicated zeolite; (c) 90-210 mins over the $500-1200 \mathrm{~cm}^{-1}$ region.

ultrasonication ( $0 \mathrm{~min}$ ), no crystalline peaks were obtained as shown in Fig. 5. The crystalline peak intensities were observed to increase as the ultrasonication time was increased. The most prominent diffraction peaks were observed for the $90 \mathrm{~min}$ ultrasonication time. The mineral phases observed in Fig. 5 were those of gismodine zeolite Na-P1 ( $2 \Theta 17,25,28,34,26,40,48,52$, $54,65,87)$. At ultrasonication periods above $90 \mathrm{~min}$, minimal crystallization was observed. This indicated that longer ultrasonication periods interfered with the nucleation process of the zeolites. Ultrasonication was shown to play a role in improving the crystallinity of zeolites, and this is in agreement with what was reported by Andac et al., ${ }^{10}$ Fernández-Jiménez et al. ${ }^{23}$ Bukari et al. ${ }^{25}$ and Belviso et al. ${ }^{26}$ Hence, the 90 min ultrasonication time was observed to be the optimum time for the formation of crystalline zeolitic phases.

The yields of the zeolites ranged from $47.6 \%-96.0 \%$. The most crystalline zeolite (ultrasonicated for $90 \mathrm{~min}$ ) was obtained with a yield of $62.0 \%$ (Table 1 ). The low yields obtained particularly for the $60 \mathrm{~min}$ and $180 \mathrm{~min}$ ultrasonicated materials, could be due to very little amounts of the solid residue zeolitic material being deposited into the filtrate solution, since ultrasonication studies were conducted on the filtrate.

Table 1 Yields of the various zeolites as ultrasonication time is varied.

\begin{tabular}{rcc}
\hline Time/h & Mass/g & Yield/\% \\
\hline 60 & 1.19 & 47.6 \\
90 & 1.55 & 62.0 \\
120 & 2.40 & 96.0 \\
180 & 1.25 & 50.0 \\
210 & 1.78 & 71.2 \\
\hline
\end{tabular}

\subsection{Percentages Mineralogical Conversion of Coal Fly Ash} into Zeolitic Phases

Table 2 is a comparison of the mineral phases present in both the CFA and the optimized zeolite ultrasonicated for $90 \mathrm{~min}$. The composition of CFA consists of spheres containing an amorphous aluminosilicate glass phase composed of mullite needles within its structure. Additionally, the quartz phase may also be embedded within the glass phase or may be found as separate particles. ${ }^{19}$ Analysis of the CFA used in this study with X-ray fluorescence indicated that the CFA was class $\mathrm{C}^{21}$, with a Si/Al ratio of 1.19 and a loss of ignition (LOI) of $3.29 \% .{ }^{21}$ The majority of CFA was composed of a larger percentage of $\mathrm{Si}^{4+}$ relative to $\mathrm{Al}^{3+}$. Similarly, the mineral phases present in CFA included mullite, quartz and aluminosilicate with percentages of $26 \%$, $28 \%$ and $46 \%$, respectively. These phases were also present in the CFA reported in the literature..$^{19,24,27}$ It was observed that the aluminosilicate, quartz and mullite phases in CFA were digested in the ultrasonicated zeolite, as shown by the percentages of 12,6 and $4 \%$, respectively, (Table 2). This observation is consistent with what was observed in Fig. 5. The dominant mineral phases observed in the ultrasonicated zeolite was the gismodine zeolite $\mathrm{Na}-\mathrm{P} 1$ phase, with the merlinoite and mordenite phases being the least abundant.

The SEM micrographs of the un-sonicated filtrate $(0 \mathrm{~min})$ and ultrasonicated filtrates were done for a duration of 90 and 210 min are shown in Fig. 6a-c), respectively. In Fig. 6a the unsonicated material was observed as irregularly shaped fusedlike grain structures. From Fig. 6a-c, morphological changes were observed in the material, indicating that sonication period played a role in the shapes of the materials studied. ${ }^{28-29}$ Separate grain-like structures became more apparent, as the ultrasonication period was increased, as seen in Fig. $6 \mathrm{~b}$ and Fig. 6c. In Fig. 6c, the grain-like structures appeared to be more uniform indicating that longer ultrasonication times influenced the distribution of the particles. 
Table 2 Percentage comparison of the mineral phases present in CFA and the zeolite crystallized at optimum conditions for $90 \mathrm{~min}$.

\begin{tabular}{lcc}
\hline \multirow{2}{*}{ Mineral phase } & \multicolumn{2}{c}{ \% Composition } \\
\cline { 2 - 3 } & CFA & Ultrasonicated zeolite \\
\hline Aluminosilicate & 46 & 12 \\
Quartz & 28 & 6.0 \\
Mullite & 26 & 4.0 \\
Hydroxysodalite & - & 5.0 \\
Faujasite & - & 13 \\
Gismondine & - & 16 \\
Analcime & - & 6.0 \\
Merlinoite & - & 4.0 \\
Mordenite & - & 2.0 \\
\hline
\end{tabular}

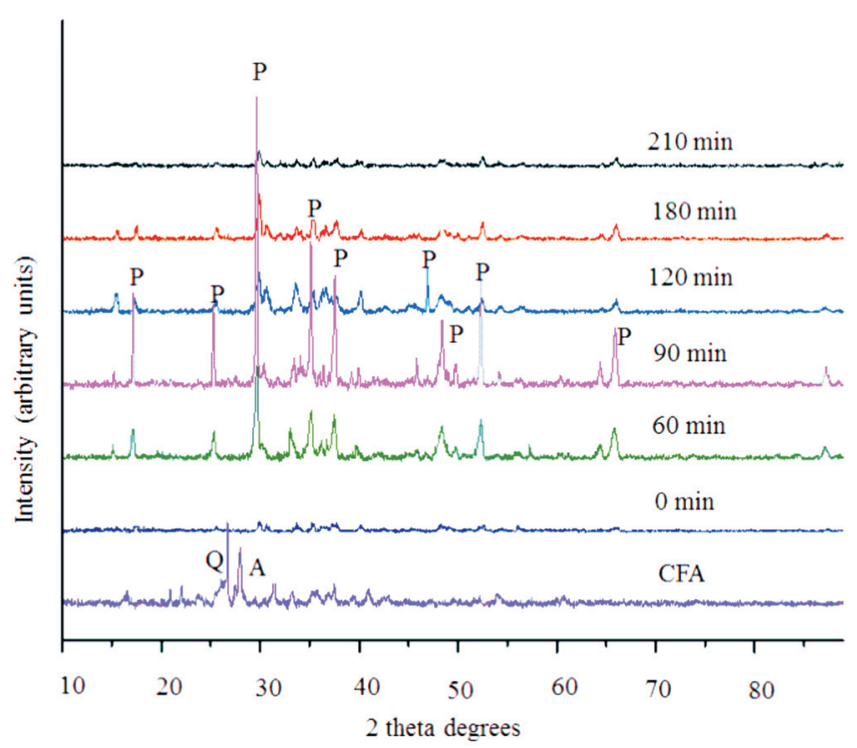

Figure 5 PXRD spectra of ultrasonicated zeolites, when the time was varied. The mineral phases are denoted as follows: the label 'P' indicates zeolite Na-P1.

The EDS spectra and the corresponding relative percentages of the elements present are shown in Fig. 7. It was observed that $\mathrm{Na}$ was the dominant element in all the characterized material followed by $\mathrm{O}$, which was derived from the $\mathrm{NaOH}$ activating solution that was filtered with the CFA slurry. Traces of Si were observed in both the un-sonicated material ( $0 \mathrm{~min}$ ) (Fig. 7a) and in the 90 min sonicated material (Fig. 7b). However, only Na and $\mathrm{O}$ were observed for the $210 \mathrm{~min}$ ultrasonicated material (Fig. 7d). It was also observed that the main elements ( $\mathrm{Na}, \mathrm{O}, \mathrm{Si}$ and $\mathrm{Al}$ ) that constituted the formation of zeolites were all present in the 90 min sonicated material as shown in Fig. 7c, with Al being approximately $0.05 \%$. The presence of zeolitic elements
( $\mathrm{Si}, \mathrm{Al}$ and $\mathrm{O}$ ), essential for the $\mathrm{Si}-\mathrm{O}-\mathrm{Al}$ network, and the zeolitic mineral phases, as highlighted in Table 2, all indicate that the obtained material is zeolite. Therefore, based on the intensity of the Na-P1 crystalline phase in the PXRD spectrum (Fig. 5) and the EDS spectra (Fig. 7), the ultrasonication time of 90 min gave the best ultrasonicated material.

\subsection{Brunauer-Emmett-Teller (BET) Analysis}

The specific surface area, pore volume and pore size distribution of 90 min ultrasonicated zeolite and parent CFA were studied using BET analysis, as shown in Table 3. The surface area of the ultrasonicated zeolite was determined to be $4.311 \mathrm{~m}^{2} \mathrm{~g}^{-1}$, while the pore volume was observed to be $0.077 \mathrm{~cm} \mathrm{~g}^{-1}$. The average pore width was $71.32 \mathrm{~nm}$. The specific surface area, the pore volume of pores and the average pore width of the ultrasonicated zeolite were observed to be greater than the CFA. Based on the comparison of the physical properties of the $90 \mathrm{~min}$ ultrasonicated zeolite and parent CFA (Table 3), the ultrasonicated zeolite could potentially be a more suiTable adsorbent for heavy metal removal than CFA.

Table 3 Values describing the physical properties of ultrasonicated zeolite based on BET studies.

\begin{tabular}{lcc}
\hline Physical properties & \multicolumn{2}{c}{ Values } \\
\cline { 2 - 3 } & CFA & Zeolite \\
\hline Specific surface area $/ \mathrm{m}^{2} \mathrm{~g}^{-1}$ & 3.314 & 4.311 \\
Single point adsorption total pore volume of pores & & \\
$/ \mathrm{cm} \mathrm{g}^{-1}$ & 0.017 & 0.077 \\
Adsorption average pore width/nm & 28.01 & 71.32 \\
\hline
\end{tabular}

\section{Conclusions}

Ultrasonication studies were conducted to determine whether the crystalline phases of zeolite could be obtained. Crystalline zeolites were obtained, with the optimum zeolite obtained after an ultrasonication time of $90 \mathrm{~min}$.

Both FT-IR and PXRD studies indicated that the zeolites ultrasonicated at a ' $\mathrm{Lo}^{\prime}$ frequency were observed to show a greater conversion of the aluminosilicate, mullite and quartz phases initially present in CFA. The phases initially in CFA were converted into gismodine zeolite - Na-P1. The SEM images showed transitions in morphologies of the sonicated materials from fused-like to separate grain-type structures as ultrasonication time was increased. The EDS spectra indicated the presence of $\mathrm{Na}, \mathrm{O}$ and $\mathrm{Si}$. The $90 \mathrm{~min}$ sonicated material had the inclusion of $\mathrm{Al}$, which was an important building-block for zeolites. Brunauer-Emmett-Teller studies conducted on the zeolite indicated that the material had a surface area, pore volume and pore size of $4.311 \mathrm{~m}^{2} \mathrm{~g}^{-1}, 0.077 \mathrm{~cm}^{3}$ and $71.31 \mathrm{~nm}$, respectively.
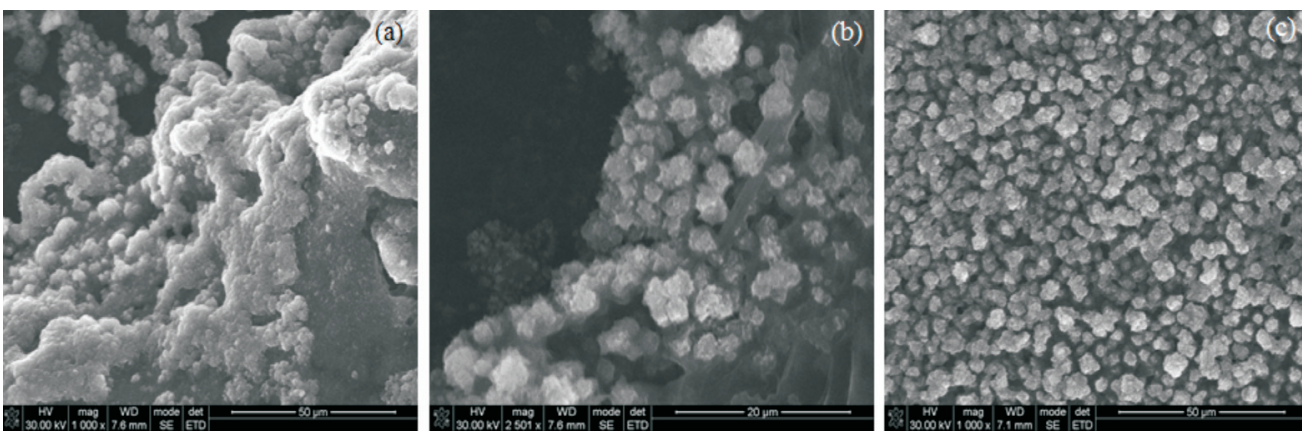

Figure 6 SEM images of (a) un-sonicated material (0 min) and sonicated materials (b) $90 \mathrm{~min}$ and (c) $210 \mathrm{~min}$. 

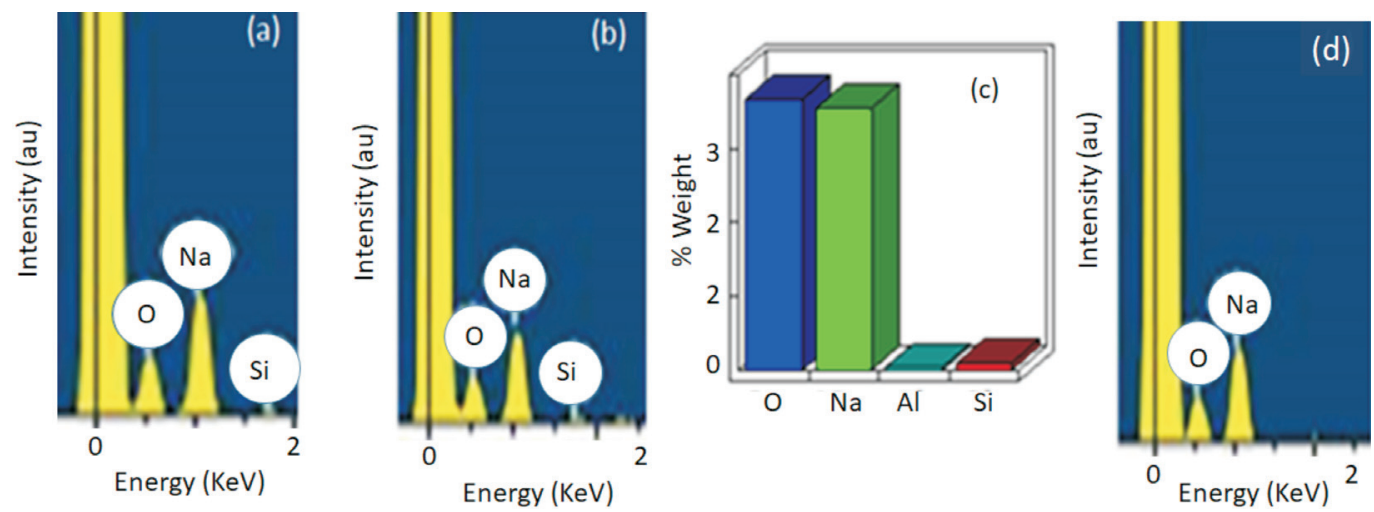

Figure 7 EDS spectra of (a) un-sonicated material (0 min) and sonicated materials for (b) 90 min including (c) the percentage composition, and (d) $210 \mathrm{~min}$.

\section{${ }^{5}$ ORCID iD}

N.T. Tavengwa: (D) orcid.org/0000-0003-4699-2394

\section{References}

1 M.J. Woo, J.Y. Seo, Y. Zhang, H. Kim, D. Lee, Y.C. Park, C. Yi, Y.S. Park and J. Moon, $\mathrm{CuY}$ zeolite catalysts prepared by ultrasonication assisted ion exchange for the oxidative carbonylation of methanol to dimethyl carbonate, Ultrason. Sonochem., 2018, 44, 146-151.

2 S.M.K. Abdoul-Fotouh, N.A.K. Aboul-Gheit and M.A. Naghmash, Dimethylether production on zeolite catalysts activated by $\mathrm{Cl}-, \mathrm{F}$ and/or ultrasonication, Fuel Chem., 2016, 44, 428-436.

3 T. Aldarhri, J. Behin, H. Kazemain and S. Rohani, Synthesis of zeolite Na-P from coal fly ash by thermo-snochemical treatment, Fuel, 2016, 182, 494-501.

4 O.D. Ozdemir and S. Piskin, A novel synthesis method of zeolite $X$ from coal fly ash: alkaline fusion folled by ultrasonic-assisted synthesis method, Water Waste Bio., 2019, 10, 143-154.

5 Z. Arruda, C.C. Nascentesa, M. Korn, C.S. Sousac and A.Z. Marco, Use of ultrasonic baths for analytical applications: a new approach for optimization conditions, J. Brazil. Chem. Soc., 2001, 12, 57-63.

6 E. Reichmanis, M. Chang, G.T. Lim and B. Park, Control of molecular ordering, alignment, and charge transport in solution-processed conjugated polymer, Thin Films., 2017, 9, 1-25.

7 G. Cravotto and P. Sintas, Power of ultrasound in organic synthesis: moving cavitational chemistry from academia to innovative and large scale applications, Chem. Soc. Rev., 2006, 35, 180-196.

8 N.S. Deora, N.N. Misra, A. Deswal, H.N. Misha and P.J. Cullen, Ultrasound for improved crystallisation in food processing, Food Eng. Rev., $2013,5,36-44$.

9 T.S. Huang, C. Xu, K. Walker, P. West and S. Zhang, Decontamination efficacy of combined chlorine dioxide with ultrasonication on apples and lettuce, J. Food Sci., 2006, 71, 134-139.

10 O. Andac, M. Tatlier, A. Sirkecioglu, I. Ece and A. Erdem-Senatalar, Effects of ultrasound on zeolite A synthesis, Micropor. Mesopor. Mat., $2005,79,225-233$.

11 F. Ali, L. Reinert, J.M. Lévêque, L. Duclaux, F. Muller, S. Saeed and S.S Shah, Effect of sonication conditions: solvent, time, temperature and reactor type on the preparation of micron sized vermiculite particles, Ultra. Sonochem., 2014, 21, 1002-1009.

12 S. Yu, Y. Zhang, Y. Ge, Y. Zhang, T. Sun, Y. Jiao and X. Zheng, Effects of ultrasound processing on the thermal and retrogradation properties of nonwaxy rice starch, J. Food Process. Eng., 2013, 36, 793-802.

13 S. Wang, Z.P. Guo, X.P. Zhang, A. Zhang and J.W Kang, On the mechanism of dendritic fragmentation by ultrasound induced cavitation, Ultra. - Sonochem., 2019, 51, 160-165.

14 T.M. Mokgehle, H. Richards, L. Chimuka, W.M. Gitari and N.T Tavengwa, Sulphates removal from AMD using CFA hydrothermally treated zeolites in column studies, Min. Eng., 2019, 141, 1-10.
15 N.M. Musyoka, L.F. Petrik, E. Hums, H. Baser and W. Schwieger, In situ ultrasonic diagnostic of zeolite $X$ crystallization with novel (hierarchical) morphology from coal fly ash, Ultrasonics, 2014, 54, 537-543.

16 S.S. Bukhari, J. Behin, H. Kazemian and S. Rohani, A comparative study using direct hydrothermal and indirect fusion methods to produce zeolites from coal fly ash utilizing single-mode microwave energy, J. Mater. Sci., 2014, 49, 8261-8271.

17 N. Murayama, H. Yamamoto and J. Shibata, Mechanism of zeolite synthesis from coal fly ash by alkali hydrothermal reaction, Int. J. Min. Process., 2002, 64, 1-17.

18 B. Jha and D.N. Singh, Fly ash zeolites innovations applications and directions, Adv. Struct. Mat., 2016, 78, 1-233.

19 W.M. Gitari, Evaluation of the Leachate Chemistry and Contaminants Attenuation in Acid Mine Drainage by Fly Ash and its Derivatives, PhD thesis, University of Cape Town, South Africa, 2006

20 J.J. Vijaya, S.K. Jesudoss, A.A Grace, L.J. Kennedy, S. Sivasanker and P. Kathirgamanathan, Hierarchical zsm-5 zeolite nanosurfaces with high porosity - structural, morphological and textural investigations, Rec. Tr. Mater. Sci. Appl., 2017, 189, 109-118.

21 N.M. Musyoka, L.F. Petrik, W.M. Gitari and G. Balfour, Optimization of hydrothermal synthesis of pure phase zeolite Na-P1 from South African coal fly ashes, J. Environ. Sci. Health, 2012, 47, 337-350.

22 V.R.K. Vadapalli, M.W. Gitari, L.F Petrik, O. Etchebers and A. Ellendt, Integrated AMD management using fly ash, J. Environ. Sci. Health, 2012, 47, 60-69.

23 A. Fernández-Jiménez and A. Palomo, Mid-infrared spectroscopic studies of alkali activated fly ash structure, Micropor. Mesopor. Mat., 2005, 86, 207-214.

24 S. Askari, S.M. Alipour, R. Halladj and M.H.D.A. Farahani, Effects of ultrasound on the synthesis of zeolites: a review, J. Por. Mat., 2013, 20, 285-302.

25 S.S. Bukhari, S. Rohani and H. Kazemian, Effect of ultrasound energy on the zeolitization of chemical extracts from fused coal fly ash, Ultrason. Sonochem., 2016, 28, 47-53.

26 C. Belviso, F. Cavalconte and S. Flore, Effects of ultrasonic treatment on zeolites synthesized from coal fly ash, Ultrason. Sonochem., 2011 , 18, 661-66 8.

27 L. Atmaja, H. Fansuri and A. Maharani, Crystalline phase reactivity in the synthesis of fly ash-based geopolymer, Fuel, 2015, 139, 59-67.

28 S.M. Solyman and H.A. Ahmed, Performance of ultrasonic-treated nano-zeolites employed in the preparation of dimethyl ether, Egyptian J. Petrol., 2013, 22, 91-99.

29 Z. Sharifalhoseini, M.H. Entezari and M. Shahidi, Sonication affects the quantity and morphology of $\mathrm{ZnO}$ nanostructures synthesized on mildsteel and changes in the corrosion protection of the surface, Ultra. Sonochem., 2018, 41, 492-502. 